\title{
Measuring Cerebrovascular Reactivity: Sixteen Avoidable Pitfalls
}

\begin{abstract}
Olivia Sobczyk $k^{1,2}$, Jorn Fierstra ${ }^{3}$, Lakshmikumar Venkatraghavan ${ }^{1}$, Julien Poublanc ${ }^{2}$, James Duffin ${ }^{1,4}$, Joseph A. Fisher ${ }^{1,4,5 *}$ and David J. Mikulis ${ }^{2,5}$

${ }^{1}$ Department of Anaesthesia and Pain Management, University Health Network, University of Toronto, Toronto, ON, Canada, 2 Joint Department of Medical Imaging and the Functional Neuroimaging Laboratory, University Health Network, Toronto, ON, Canada, ${ }^{3}$ Department of Neurosurgery, University Hospital Zurich, Zürich, Switzerland, ${ }^{4}$ Department of Physiology, University of Toronto, Toronto, ON, Canada, 5 Institute of Medical Science, University of Toronto, Toronto, ON, Canada
\end{abstract}

An increase in arterial $\mathrm{PCO}_{2}$ is the most common stressor used to increase cerebral blood flow for assessing cerebral vascular reactivity (CVR). That $\mathrm{CO}_{2}$ is readily obtained, inexpensive, easy to administer, and safe to inhale belies the difficulties in extracting scientifically and clinically relevant information from the resulting flow responses. Over the past two decades, we have studied more than 2,000 individuals, most with cervical and cerebral vascular pathology using $\mathrm{CO}_{2}$ as the vasoactive agent and blood oxygen-leveldependent magnetic resonance imaging signal as the flow surrogate. The ability to deliver different forms of precise hypercapnic stimuli enabled systematic exploration of the blood flow-related signal changes. We learned the effect on CVR of particular aspects of the stimulus such as the arterial partial pressure of oxygen, the baseline $\mathrm{PCO}_{2}$, and the magnitude, rate, and pattern of its change. Similarly, we learned to interpret aspects of the flow response such as its magnitude, and the speed and direction of change. Finally, we were able to test whether the response falls into a normal range. Here, we present a review of our accumulated insight as 16 "lessons learned." We hope many of these insights are sufficiently general to apply to a range of types of $\mathrm{CO}_{2}$-based vasoactive stimuli and perfusion metrics used for CVR.

Keywords: carbon dioxide, cerebral blood flow, vascular responses, cerebrovascular reactivity, cerebrovascular reactivity to carbon dioxide

\section{INTRODUCTION}

For the last two decades, our laboratory has been engaged in interrogating cerebral vascular function. The overarching approach has been to observe changes in regional brain flow in response to a vasoactive stimulus. This is referred to as cerebrovascular reactivity, or cerebral vascular reactivity (CVR). There are a variety of well-described vasoactive stimuli and outcome measures. Our laboratory employs precise targeting of end-tidal $\mathrm{PCO}_{2}\left(\mathrm{P}_{\mathrm{ET}} \mathrm{CO}_{2}\right)$ and blood oxygen-level-dependent (BOLD) magnetic resonance imaging (MRI) as the surrogate measure of cerebral blood flow (CBF). The ability to precisely duplicate a stimulus has enabled us to, retrospectively and prospectively, re-examine the way we generate and interpret our data. Indeed, over time we have identified unwarranted assumptions-including some in which we had high levels of confidence that led to weak methodology and misguided data analysis, and conclusions, regrettably, some after they appeared in our own published work. We have 
published most of these insights in multiple separate papers. Nevertheless, we thought that it would be useful to the CVR community for us to review these insights in summary format in one paper. We believe the principles can selectively inform on the strengths and limitations of other CVR studies performed under a range of stimuli such as infusion of acetazolamide, breath hold, inspiration of fixed inspired $\mathrm{PCO}_{2}\left(\mathrm{FICO}_{2}\right)$, and with the use of outcome measures such as transcranial Doppler (TCD) and various MRI methods.

\section{Stimulus Response}

Cerebral vascular reactivity is a provocative cerebral vascular test analogous to a cardiac stress test. For both, provocation is required to elicit a flow response exceeding baseline perfusion to ascertain the flow reserve. In the case of the cardiac stress testing, treadmill exercise or vasoactive agent stressors indicate the presence of flow deficits in the form of chest pain, ECG changes, or flow reductions in cardiac perfusion imaging. The results are then interpreted using angiographic findings of the vascular patho-anatomy.

\section{Stressors}

For studies of the heart, a standard stimulus may consist of aerobic exercise pushed to the threshold where anaerobic metabolism becomes active. When using pharmacological vasoactive agents such as adenosine, regadenoson, and dipyridamole as standard stimuli, uniformity of the vasodilatory stimulus is achieved by supramaximal dosing, that is, the dose beyond which no further flow response occurs.

In the brain, activation of neurovascular coupling throughout the brain is not an option as there is no safe stimulus that can activate all neurons. However, global vasoactive stimulation can be affected pharmacologically by the intravenous injection of hypotensive agents or using carbonic anhydrase blockers such as acetazolamide. The former is not considered safe for this indication. Acetazolamide can be injected at supramaximal response doses, but its time course is not predictable (Dahl et al., 1995; Grossmann and Koeberle, 2000) and results in frequent uncomfortable side effects (Ringelstein et al., 1992; Dahl et al., 1995; Grossmann and Koeberle, 2000; Saito et al., 2011).

Hypercapnia, defined an increased arterial partial pressure of $\mathrm{CO}_{2}\left(\mathrm{PaCO}_{2}\right)$, is easily implemented, safe, well-tolerated, and is therefore, the most used stressor. Each $\mathrm{mmHg}$ increase in $\mathrm{PaCO}_{2}$ increases CBF by $\sim 6-8 \%$ (Kety and Schmidt, 1948; Willie et al., 2012; Al-Khazraji et al., 2019). Supramaximal levels of $\mathrm{PaCO}_{2}$ (greater than $90 \mathrm{mmHg}$ (Reivich, 1964) cannot be used to obtain a standard stimulus as levels that exceed 50-60 $\mathrm{mmHg}$ are very uncomfortable (Willie et al., 2012) and levels acutely exceeding $\sim 80 \mathrm{mmHg}$ begin to cause confusion

Abbreviations: BOLD, blood oxygen-level dependent; CBF, cerebral blood flow; $\mathrm{CVR}$, cerebrovascular reactivity; $\mathrm{FICO}_{2}$, fractional concentration of inspired carbon dioxide; $\mathrm{P}_{\mathrm{ET}} \mathrm{CO}_{2}$, end-tidal partial pressure of carbon dioxide; MAP, mean arterial pressure; MCA, middle cerebral artery; $\mathrm{MCAv}$, middle cerebral artery velocity; MRI, magnetic resonance imaging; $\mathrm{PaCO}_{2}$, arterial partial pressure of carbon dioxide; ROI, region of interest; SGD, sequential gas delivery. and unconsciousness. However, implementation of a known stimulus requires the ability to precisely target $\mathrm{PaCO}_{2}$. This is not a trivial task. First, while it may seem that $\mathrm{PaCO}_{2}$ should simply be a function of the inspired fractional concentration of $\mathrm{CO}_{2}\left(\mathrm{FICO}_{2}\right)$, it is in fact also a function of the minute ventilation, which itself changes when inhaling $\mathrm{CO}_{2}$ (Fisher, 2016). Since the change in minute ventilation in response to a change in $\mathrm{FICO}_{2}$ cannot be predicted, $a$ particular $\mathrm{PaCO}_{2}$ cannot be targeted by designating the $\mathrm{FICO}_{2}$ (Peebles et al., 2007).

Measuring $\mathrm{PaCO}_{2}$, the independent variable of $\mathrm{CBF}$, is problematic. The only non-invasive measure of $\mathrm{PaCO}_{2}$ available is the $\mathrm{P}_{\mathrm{ET}} \mathrm{CO}_{2}$, but, unfortunately, without rebreathing, it is not a reliable surrogate for $\mathrm{PaCO}_{2}$ (Jones et al., 1972). The $\mathrm{P}_{\mathrm{ET}} \mathrm{CO}_{2}$ does approach $\mathrm{PaCO}_{2}$ only with complete rebreathing (Duffin and McAvoy, 1988), and prospective targeting using sequential gas delivery (SGD; Ito et al., 2008; Fisher et al., 2016). End-tidal forcing (Robbins et al., 1982) is able to target $\mathrm{P}_{\mathrm{ET}} \mathrm{CO}_{2}$, but its equivalence to $\mathrm{PaCO}_{2}$ has not been demonstrated (Jones et al., 1972; McDonald et al., 2002; Tymko et al., 2016). When using breath hold as the vasoactive stimulus, the $\mathrm{P}_{\mathrm{ET}} \mathrm{CO}_{2}$ is related to breath hold duration, but $\mathrm{PaCO}_{2}$ is unknown (Totaro et al., 1999).

\section{Stress Indicators}

The stress indicator, $\mathrm{CBF}$, is measured indirectly by surrogate measures. All surrogates can be characterized by fidelity to flow and their limitations in this regard. TCD measures velocity with high temporal resolution. The output, however, reflects velocity only in a single arterial segment rather than the brain parenchyma. Even so, its relation to flow assumes no particular corresponding change in vessel diameter with the stimulus, which may not hold (Willie et al., 2012; Verbree et al., 2014; Al-Khazraji et al., 2019). In our laboratory, we use BOLD signal changes as surrogates for changes in flow. These signals have high temporal resolution and high spatial resolution, providing whole brain maps of tissue perfusion. Although BOLD reflects flow-induced deoxyhemoglobin dilution, to its credit the signal has a reasonably linear relation to flow at moderate levels of hypercapnia (Hoge et al., 1999). Both TCD and BOLD are internally consistent but are poorly correlated (Burley et al., 2020). Arterial spin labeling uses magnetic labeling of water protons as a flow tracer and is a very good measure of flow. However, its limitations for CVR include imperfect labeling efficiency that can change from patient to patient based on difference in anatomy, and the magnetic label decays as a function of T1-relaxation over time. Delays in arrival time caused by steno-occlusive disease can result in problems with labeled proton localization and increasing image noise.

\section{CVR MEASURES}

\section{Basic CVR Measures}

Failing precise targeting of $\mathrm{PaCO}_{2}$, a reasonable fallback position is to assume that the $\Delta \mathrm{P}_{\mathrm{ET}} \mathrm{CO}_{2}$ is close to $\Delta \mathrm{PaCO}_{2}$ and therefore can be used to index the change in flow for the stimulus by dividing it by $\Delta \mathrm{P}_{\mathrm{ET}} \mathrm{CO}_{2}$ and defining the 


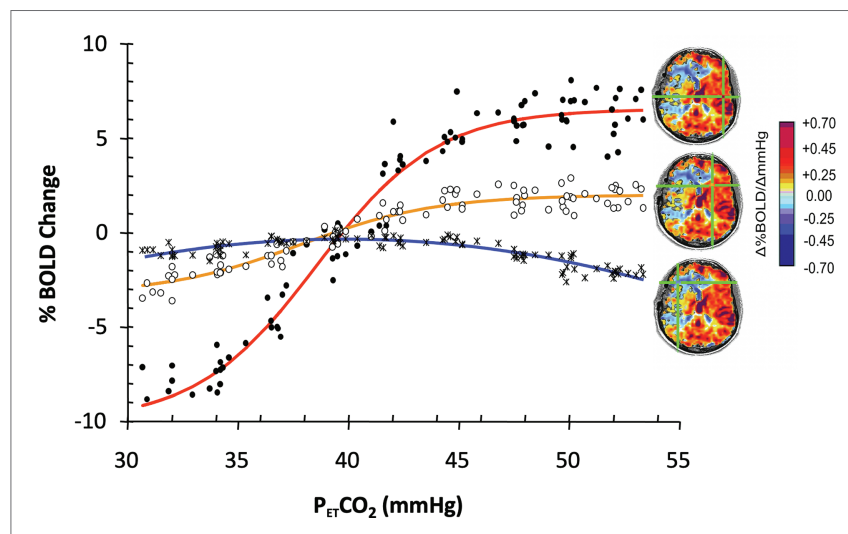

FIGURE 1 | The effect of progressive weakening of vascular response to $\mathrm{PaCO}_{2}$ on the calculation of cerebral vascular reactivity (CVR). Data show blood oxygen-level-dependent (BOLD) responses to a range of $\mathrm{P}_{\mathrm{ET}} \mathrm{CO}_{2}$ in selected ROI in an 18-year-old male with moyamoya disease affecting predominantly the right MCA territory. With progressively weaker vascular responsiveness, the sigmoid relationship (red curve from healthy cortex) weakens, the slope flattens (yellow curve, from moderately compromised territory), and finally, flow decreases instead of increases (steal: blue curve, severely compromised territory) in favor of the more robust vascular beds. Overall fitting a straight line to the data between $\mathrm{P}_{\mathrm{ET}} \mathrm{CO}_{2} 40$ and $50 \mathrm{mmHg}$ results in a good fit for the red and yellow lines, less so for the biphasic blue line with slope depending on baseline and the highest $\mathrm{PaCO}_{2}$. Modified from Sobczyk et al. (2014).

stress indicator as the slope of line of best fit, CVR (Vesely et al., 2001; Sobczyk et al., 2014).

We initially considered the magnitude of the CVR as reflecting the vasodilatory vigor of the underlying vasculature (Bhogal et al., 2014). In patients with known vascular pathology, we identified specific regions of interest (ROI) in some patients where, rather than flow increasing in response to a stressor, it declined. Such areas of "steal" in response to hypercapnia had been described more than 40 years ago (Brawley, 1968; Symon, 1969) and have been reviewed recently (Fisher et al., 2018).

\section{Enhanced CVR Model and Physiological Interpretations}

We also developed a more comprehensive model to explain additional behaviors of the vasculature during hypercapnia. This model consisted of blood vessels organized in a series of hierarchical vascular beds where each downstream bed has a greater flow potential than its supply vessels (Duffin et al., 2017, 2018). Consequently, on the application of a vasoactive stimulus, vascular territories perfused in parallel from a common source must compete for inflow such that increased inflow to beds capable of more robust vasodilation is at the expense of those with less robust vasodilation, i.e., with steal (Sobczyk et al., 2014). The presence of steal is known to be a strong marker for risk of stroke (Reinhard et al., 2014) and is therefore important to identify. Importantly, the absence of steal indicates sufficient collateral blood flow to meet the flow requirements downstream from the stenosis and seems protective for stroke (Bang et al., 2008; Sheth et al., 2016; Tan et al., 2016).
This view is the basic model we followed in studying CVR in the first 434 patients examined (Spano et al., 2013). While maintaining consistency in the methodology of our studies, we nevertheless explored alternatives to our initial underlying assumptions. The aim of the remainder of this paper assembles some of the subtle, but retrospectively obvious lessons we learned over the last two decades about optimizing the stressor, developing new stress indicators, and furthering the understanding of cerebral vascular physiology.

\section{The Two-Point Stimulus}

As defined above, the vasoactive stimulus is the $\mathrm{PaCO}_{2}$. Note that when the hypercapnic stressor is implemented by breath hold or fixing the $\mathrm{FICO}_{2}$, the magnitude of the stressor, that is, the change in the independent variable $\mathrm{PaCO}_{2}$, is unknown. With breath hold, $\triangle \mathrm{CBF}$ is a function of time and can only be indexed by breath hold duration, which correlates poorly with $\Delta \mathrm{PaCO}_{2}$. For $\mathrm{FICO}_{2}$ inhalation, $\Delta \mathrm{P}_{\mathrm{ET}} \mathrm{CO}_{2}$ is known, but not $\Delta \mathrm{PaCO}_{2}$. As such, CVR can only have a binary outcome: either positive or negative (steal absent or present). This information is retained despite the uncertainty in $\Delta \mathrm{PaCO}_{2}$ because the denominator $\Delta \mathrm{P}_{\mathrm{ET}} \mathrm{CO}_{2}$ is always positive, leaving the sign of the slope to depend only on the numerator, $\triangle \mathrm{CBF}$.

\section{CVR Beyond the Two-Point Stimulus}

To obtain information beyond this binary labeling, we set out to address one major unknown by precisely targeting the $\mathrm{PaCO}_{2}$. For this purpose, we developed a system involving SGD (Slessarev et al., 2007; Fisher et al., 2016). SGD enables the establishment of $\mathrm{P}_{\mathrm{ET}} \mathrm{CO}_{2}$ within $2 \mathrm{mmHg}$ of a target, independent of the level and pattern of breathing. A further benefit of SGD is that the difference between $\mathrm{P}_{\mathrm{ET}} \mathrm{CO}_{2}$ and $\mathrm{PaCO}_{2}$ falls within the range of error of the blood gas analyzer, making the equivalent value to $\mathrm{PaCO}_{2}$ accessible non-invasively (Ito et al., 2008; Fierstra et al., 2011, 2013). Also employing SGD, Willie et al. (2012) reported a regression of $\mathrm{PaCO}_{2}$ vs. $\mathrm{P}_{\mathrm{ET}} \mathrm{CO}_{2}$ over a range of 15-65 mmHg had slope 0.88 with a $r^{2}$ of 0.98 and Bland-Altman analysis showing a bias where $\mathrm{P}_{\mathrm{ET}} \mathrm{CO}_{2}$ exceeded $\mathrm{PaCO}_{2}$ by about $5 \mathrm{mmHg}$ at the highest $\mathrm{PCO}_{2}$ levels.

Note that henceforth in this paper, when referring to a stressor administered via SGD, we will cite $\mathrm{PaCO}_{2}$ when referring to the stimulus and $\mathrm{P}_{\mathrm{ET}} \mathrm{CO}_{2}$ when referring to the measured parameter.

\section{CVR in Health}

In healthy people the relationship between $\mathrm{PaCO}_{2}$ and $\mathrm{CBF}$ is sigmoidal with a midpoint close to baseline $\mathrm{PaCO}_{2}$ showing vasodilatory and vasoconstrictor reserves (Battisti-Charbonney et al., 2011; Bhogal et al., 2014; Duffin et al., 2017). The sigmoid response characteristics vary between white matter and gray matter (Bhogal et al., 2015) and indeed between more specific anatomical locations (Sobczyk et al., 2015; van Niftrik et al., 2017; Duffin et al., 2018). Nevertheless, in health, the slope of a voxel-wise line of best fit between $\mathrm{P}_{\mathrm{ET}} \mathrm{CO}_{2}$ and $\mathrm{CBF}$ provides a reasonably accurate, simplifying, linear representation of the sigmoidal $\mathrm{CO}_{2}$-CBF response (Bhogal et al., 2014; Sobczyk et al., 2014). Sobczyk et al. (2015) and McKetton et al. (2018) 


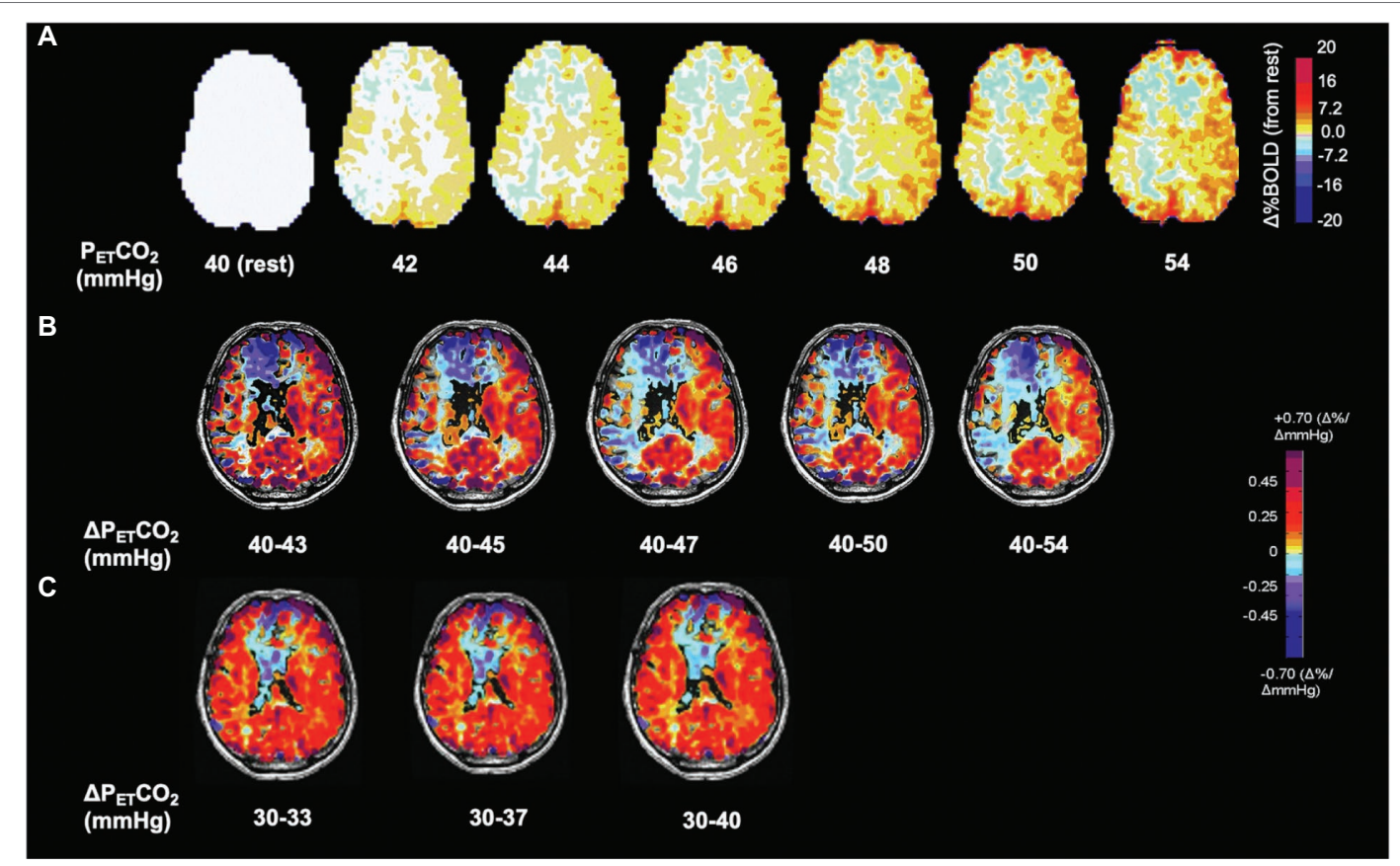

FIGURE 2 | Voxel-wise changes of BOLD signal and CVR as a function of $\triangle \mathrm{P}_{\mathrm{ET}} \mathrm{CO}_{2}$ in the hypocapnic and hypercapnic range. Same subject as Figure 1. (A) BOLD signal change in \% from baseline $\mathrm{P}_{\mathrm{ET}} \mathrm{CO}_{2} 40 \mathrm{mmHg}$ shown in interval increases of $2 \mathrm{mmHg}$. Note progressive changes in BOLD signal at every increment of $\mathrm{P}_{\mathrm{ET}} \mathrm{CO}_{2}$ of $2 \mathrm{mmHg}$. (B) Effect of CVR calculated as $\triangle \mathrm{BOLD} / \triangle \mathrm{P}_{\mathrm{ET}} \mathrm{CO}_{2}$ on differences in $\triangle \mathrm{P}_{\mathrm{ET}} \mathrm{CO}_{2}$. Note increases in the extent of steal with greater changes in $\mathrm{PaCO}_{2}$ demonstrating its shortcomings for normalization for $\triangle \mathrm{P}_{\mathrm{ET}} \mathrm{CO}_{2}$. Standardization therefore results from using a reproducible stimulus. (C) CVR in the hypocapnic range is radically different from the hypercapnic range (see also Figure 3). Respective color scales on right.

have provided an atlas mapping normative CVR with voxelwise mean $\pm \mathrm{SD}$ for CVR in health.

\section{CVR in Neurovascular Disease}

\section{The Shape of the $\mathrm{PCO}_{2}$-Flow Relationship}

In the presence of neurovascular disease, the sigmoidal relationship of flow to $\mathrm{PaCO}_{2}$ is degraded such that curves become flattened (Harper and Glass, 1965; Ringelstein et al., 1988; Sobczyk et al., 2014). Figure 1 represents flow in selected voxels over a range of $\mathrm{PaCO}_{2}$ in a patient with cerebrovascular disease.

Note that a suitably strong stressor is required to stimulate a sufficiently robust vasodilation in healthier vascular territories such that blood flow is preferentially directed to those territories and away from those with a weaker vasodilatory response, resulting in reduced flow or steal. The greater the vasodilation in the healthy vasculature, the greater the sensitivity for exposure of vasodilatory reserve (Figure 2).

From these considerations, we have the first four lessons:

1. When $\mathrm{CBF}$ responses to changes in $\mathrm{P}_{\mathrm{ET}} \mathrm{CO}_{2}$ are curved, a two-point stressor will result in a reduced CVR.

2. The less sigmoidal the flow vs. $\mathrm{PaCO}_{2}$ curve, the more tenuous the connection between the CVR calculation and the vascular reactivity and the more the CVR is affected by the initial $\mathrm{PaCO}_{2}$ and $\triangle \mathrm{PaCO}_{2}$ (see Figure 2).

3. Small differences in the $\Delta \mathrm{PaCO}_{2}(\sim 2 \mathrm{mmHg})$ result in measurable changes in CVR throughout the hypocapnic and hypercapnic ranges (Figure 2).
4. The CVR depends on whether the $\triangle \mathrm{PaCO}_{2}$ is applied in the hypocapnic or hypercapnic range and the direction of change (see also Ide et al., 2003; Coverdale et al., 2014; Figure 3).

\section{ASPECTS OF THE STIMULUS AFFECTING CVR}

\section{Baseline $\mathrm{PCO}_{2}$ and CVR}

Following from (2): What baseline $\mathrm{PCO}_{2}$ should be used for measuring CVR? In the first decade, we assumed that the normal $\mathrm{PCO}_{2}$ for humans was nominally $40 \mathrm{mmHg}$ and would provide a universal starting point. However, over the years we found that resting $\mathrm{P}_{\mathrm{ET}} \mathrm{CO}_{2}$ varied between $30 \mathrm{mmHg}$ and over $47 \mathrm{mmHg}$, but each baseline $\mathrm{P}_{\mathrm{ET}} \mathrm{CO}_{2}$ remained mostly constant over time, in some people over the many years in which we followed them.

The alternate approach we considered was that of identifying a participant's resting $\mathrm{PCO}_{2}$ and applying a stimulus from resting $\mathrm{P}_{\mathrm{ET}} \mathrm{CO}_{2}$ to resting $+10 \mathrm{mmHg}$. It was counterintuitive that a $\mathrm{P}_{\mathrm{ET}} \mathrm{CO}_{2}$ stressor of $34 \mathrm{mmHg}$ to $44 \mathrm{mmHg}$ in one person with resting $\mathrm{P}_{\mathrm{ET}} \mathrm{CO}_{2}$ of $34 \mathrm{mmHg}$ would be equivalent to one of $44 \mathrm{mmHg}$ to $54 \mathrm{mmHg}$ in another with resting $\mathrm{P}_{\mathrm{ET}} \mathrm{CO}_{2}$ of $44 \mathrm{mmHg}$. However, over time we were convinced that this was indeed the case and changed to a stressor $\mathrm{P}_{\mathrm{ET}} \mathrm{CO}_{2}$ spanning the range from baseline to baseline $+10 \mathrm{mmHg}$. Figure 4 is a vivid illustration of the wisdom of this approach. These findings are consistent with the idea that people normalize their resting 


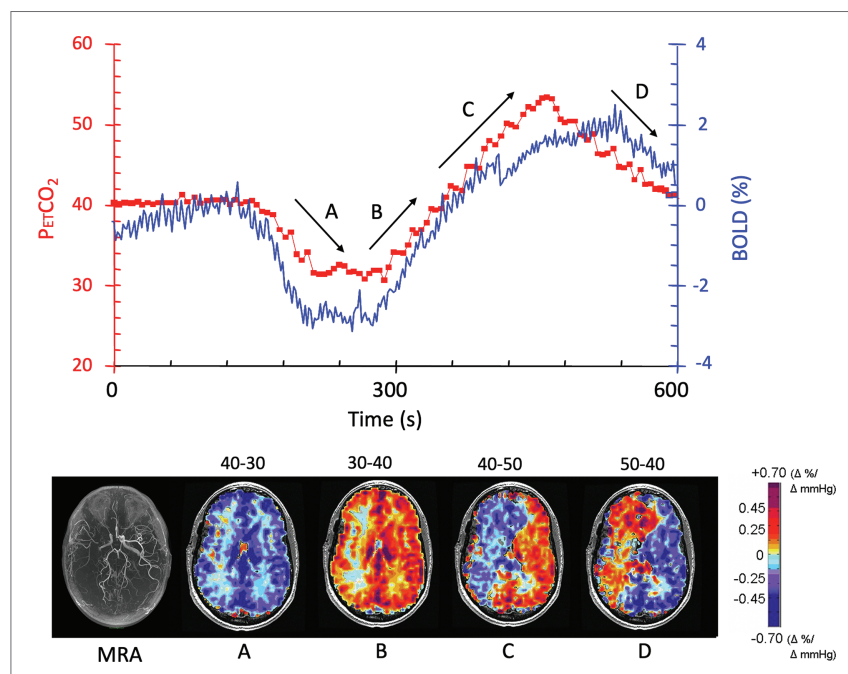

FIGURE 3 | The effect of direction of change of $\mathrm{PaCO}_{2}$ on CVR. The patient is the same individual whose data are shown in Figures 1, 2. The experimental paradigm of changes in $\mathrm{P}_{\mathrm{ET}} \mathrm{CO}_{2}$ is shown in red in the graph; BOLD signal changes are shown in blue. CVR maps shown in the lower figure correspond to the periods depicted on the graph, with arrows showing the direction of change in $\mathrm{P}_{E T} \mathrm{CO}_{2}$. (A) As $\mathrm{P}_{E T} \mathrm{CO}_{2}$ is reduced from $40 \mathrm{mmHg}$ to $30 \mathrm{mmHg}$, there is a symmetrical reduction in BOLD signal in the white and gray matter in both hemispheres. (B) The mirror image change in $\mathrm{P}_{\mathrm{ET}} \mathrm{CO}_{2}$ from $30 \mathrm{mmHg}$ to $40 \mathrm{mmHg}$ results in an asymmetrical change where flow increases in the left hemisphere while decreasing in the right (steal). (C) Continuation of increase in $\mathrm{P}_{\mathrm{ET}} \mathrm{CO}_{2}$ to $50 \mathrm{mmHg}$ exacerbates the flow discrepancies. (D) Reducing the $\mathrm{P}_{\mathrm{ET}} \mathrm{CO}_{2}$ from $50 \mathrm{mmHg}$ to $40 \mathrm{mmHg}$ reduces flow in the healthier left hemisphere as expected when $\mathrm{P}_{\mathrm{ET}} \mathrm{CO}_{2}$ falls. However, the blood vessels in right hemisphere paradoxically increase their flow, a feature attributed to the improved perfusion pressure as left hemisphere vessels constrict. Modified from Sobczyk et al. (2014).

vascular tone to their resting $\mathrm{PCO}_{2}$ which they retain for years as indicated by full metabolic compensations and are not at all committed to some arbitrary "normal" value in textbooks.

From these considerations, we have the fifth lesson:

5. For accuracy of CVR and comparability between subjects, the baseline for CVR measurement should be the resting $\mathrm{P}_{\mathrm{ET}} \mathrm{CO}_{2}$.

\section{Effect of Blood Pressure on CVR}

The brain is protected from hypoperfusion resulting from reductions in perfusion pressure by reflex vasodilation, mostly of small arterioles $(50-200 \mu \mathrm{m})$ downstream from pial vessels $(\sim 300 \mu \mathrm{m}$; Kontos, 1989), a response termed "autoregulation" (Kulik et al., 2008). Hypercapnia is distressing for some subjects, and a few may respond with increases in blood pressure. Hypercapnia dilates both the pial and penetrating arterioles, blunting the autoregulatory vasoconstriction restraining increases in $\mathrm{CBF}$ due to increases in blood pressure. In the presence of hypercapnia, an apparent "autoregulatory break-through" may occur, as depicted in Figure 5.

From these considerations, we have the sixth lesson:

6. Monitor blood pressure during assessment of CVR. Interpret flow results in the presence of hypercapnia and hypertension with caution.

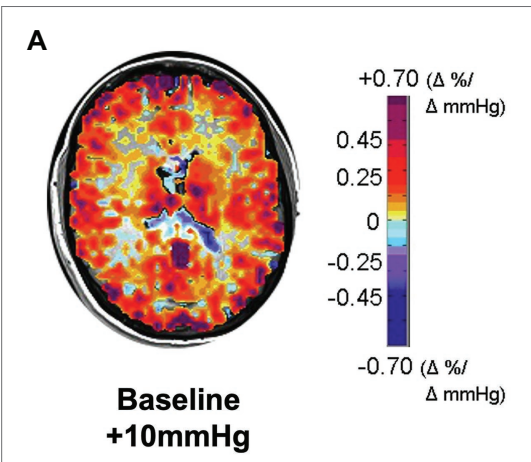

B

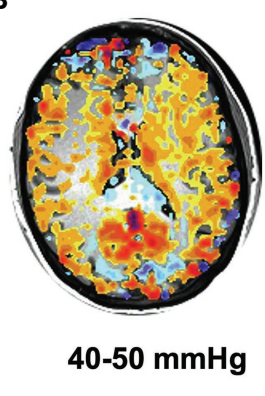

FIGURE 4 | CVR responses to two $10 \mathrm{mmHg}$ increases in $\mathrm{P}_{\mathrm{ET}} \mathrm{CO}_{2}$ : (A) from subject's actual baseline to baseline $+10 \mathrm{mmHg}$, showing higher CVR;

(B) from 40 to $50 \mathrm{mmHg}$, showing that CVR is globally reduced. Subject was a healthy active 30-year-old female with resting $\mathrm{P}_{\mathrm{ET}} \mathrm{CO}_{2}$ ranging between 28 and $30 \mathrm{mmHg}$ on different days, verified by a direct measure of $\mathrm{PaCO}_{2}$; her commensurately reduced bicarbonate level indicated that this was a longstanding condition, not due to acute hyperventilation.

\section{The Effect of $\mathrm{PO}_{2}$ on CVR}

When administering a fixed $\mathrm{FICO}_{2}$ such as "carbogen" (5\% $\mathrm{CO}_{2}$ ), whether the balance is composed of air or $\mathrm{O}_{2}$ is consequential. If the balance is $\mathrm{O}_{2}$, then compared to the balance being air, there will be a higher ventilatory response and, as a result, a smaller $\Delta \mathrm{PaCO}_{2}$ (Prisman et al., 2007; Fisher, 2016) and therefore a smaller $\Delta \mathrm{CBF}$. Concurrent hypoxia to arterial saturations below $70 \%$ may also increase the $\mathrm{CBF}$ response to hypercapnia (Poulin et al., 1996; Ainslie and Burgess, 2008; Mardimae et al., 2012; Willie et al., 2012).

Accordingly, seventh and eighth lessons are:

7. With fixed $\mathrm{FICO}_{2}$, the minute ventilation, and therefore the $\mathrm{PaCO}_{2}$, depends on the inspired $\mathrm{PO}_{2}$ and ventilatory response, neither of which can be predicted or corrected post hoc. This confounder should be considered for all fixed $\mathrm{FICO}_{2}$ protocols.

8. A fixed inspired $\mathrm{PO}_{2}$ does not result in a fixed arterial $\mathrm{PO}_{2}$; the latter varies depending on the level of ventilation in a mechanism analogous to that of breathing a fixed $\mathrm{FICO}_{2}$. Such small changes in $\mathrm{PO}_{2}$ due to differences in ventilation have inconsequential changes for the CVR.

\section{Non-sigmoidal Flow Responses and Calculation of CVR}

In our early investigations of the way in which $\mathrm{CBF}$ responds to $\mathrm{PaCO}_{2}$, we applied a gradual "ramp" increase in $\mathrm{PaCO}_{2}$ from resting baseline to baseline $+15 \mathrm{mmHg}$ over $4 \mathrm{~min}$ (Sobczyk et al., 2014). The results made it clear that, in the presence of cerebrovascular disease, many vascular beds, some as large as an entire hemisphere, have complex flow responses that are decidedly not sigmoidal, nor could they be accurately summarized by a linear regression. We studied the voxel-byvoxel changes in signal over the range of $\mathrm{P}_{\mathrm{ET}} \mathrm{CO}_{2}$ (Fisher et al., 2017) and were able to classify the $\mathrm{P}_{\mathrm{ET}} \mathrm{CO}_{2}$ response patterns 


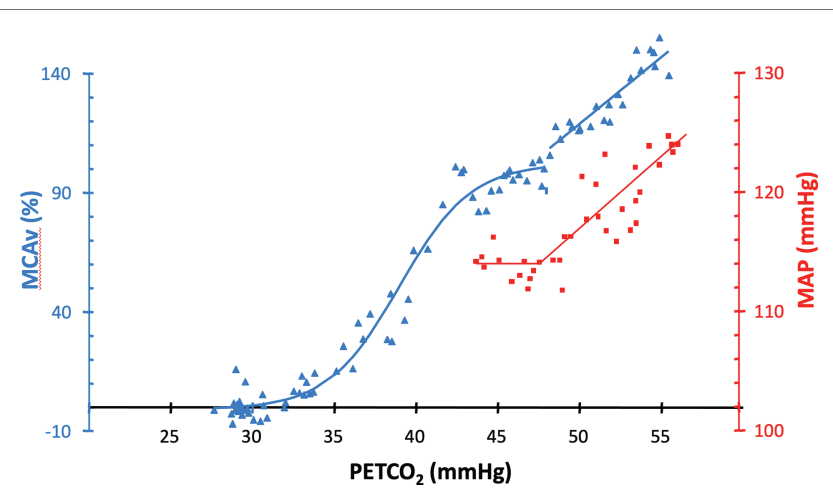

FIGURE 5 | MAP (squares) and \%MCAv (triangles) responses to increases in $\mathrm{P}_{\mathrm{ET}} \mathrm{CO}_{2}$ in a healthy subject. In the presence of hypercapnia, an apparent "autoregulatory break-through" occurs in this subject at approximately $47 \mathrm{mmHg}$. Figure recreated and modified from Battisti-Charbonney et al. (2011).

into four basic types: proportional to $\mathrm{PaCO}_{2}$, biphasic rise-fall, negatively proportional to $\mathrm{PaCO}_{2}$, and biphasic fall-rise (Figure 6).

By investigating the frequency and distribution of the various response patterns in healthy subjects and patients with cerebrovascular steno-occlusive disease, we found that the response types were not dispersed throughout the brain, but tended to cluster in large contiguous regions, strongly suggesting shared physiologic causes. Analyzing the biphasic curves as a linear regression can obscure important physiological information from the subsequently derived CVR maps (Fisher et al., 2017). Rather, multimodal analysis (transfer function analysis (Duffin et al., 2015) or vascular resistance analysis (Duffin et al., 2017, 2018) can be used to extract abundant additional nuanced information regarding vascular response functions.

From these investigations, we derived the additional lessons:

9. A ramp stimulus reveals the pattern of response to a range of $\mathrm{PaCO}_{2}$ values.

10. A ramp stimulus to a $\mathrm{PaCO}_{2}>10 \mathrm{mmHg}$ above resting explores a higher range of vasodilatory reserve. This range of reserve would not be interrogated with a smaller stressor such as $5 \mathrm{mmHg}$.

11. A ramp stimulus generates the data in a form that can be analyzed for intrinsic vascular resistance (Duffin et al., 2017, 2018; McKetton et al., 2019).

\section{A NEW CVR METRIC: SPEED OF RESPONSE}

The calculation of CVR as the slope of a regression between $\mathrm{PaCO}_{2}$ and flow becomes progressively less representative of vascular reactivity as the correlation diminishes. However, another, less apparent factor also affects the quality of representation, and likely a reliable indicator of vascular health in its own right-duration of full evolution of the CVR response after stimulus onset, i.e., the "speed of response."
The effect of a slow response on the calculation of CVR is shown in Figure 7. The slow vascular response to a step change in $\mathrm{P}_{\mathrm{ET}} \mathrm{CO}_{2}$ (Figure 7A1, green line) graphs a large range of delayed changes in BOLD signal at the $50-\mathrm{mmHg}$ position on the abscissa (Figure 7A3, black dots) reducing the slope of the line of regression, compared to that of a rapid response (Figure 5 row B, red line, black dots). Clearly, a simple regression of all data points is not an accurate summary of the vascular response when the vascular response time to the stimulus is prolonged; a correction is therefore required.

\section{Mathematical Correction of CVR for the Speed of Response}

In Figure 7 we show the mathematical approach of Poublanc et al. (2015) for correcting CVR for a slow response. This process entails assuming the response is a first-order exponential and obtaining an index of that delay in the form of $\tau$, the time constant required to match the response to the exponential function (Figures 7A2,B2). Caveat: Heretofore, we have used the input function containing both the rising and declining $\mathrm{PaCO}_{2}$ in the calculation of $\tau$ in response to the step change in $\mathrm{PaCO}_{2}$. This method assumes $\tau$ is the same in both directions. Figures 2, 3 provide reason to challenge this assumption in future analysis. Further mathematical treatments are needed. Transfer function analysis can be used to identify phase, gain, and coherence metrics (Duffin et al., 2015). Sinusoidal stimuli may be used (Blockley et al., 2011), and the linear fit between the observed BOLD signal and the arrival-time adjusted $\mathrm{P}_{\mathrm{ET}} \mathrm{CO}_{2}$ convolved with the hemodynamic response function (Yao et al., 2021).

\section{Physical Correction of CVR for the Speed of Response}

The amplitude of CVR can also be corrected for speed of response by changing the $\mathrm{P}_{\mathrm{ET}} \mathrm{CO}_{2}$ vs. time profile of the stressor from a step to a ramp (Figure 8). In the case of a slowly rising stressor, the effect of slowed response times on the CVR is reduced, resulting in an accurate calculation of amplitude of CVR (Poublanc et al., 2015).

\section{Speed of Response as a Metric of Vascular Health}

How quickly the vascular resistance in a voxel changes may be a metric of neurovascular health. We frequently observed a strong correlation between speed of response, CVR, and known vascular pathology. Our current impression is that of these three, the speed of response is the most sensitive to mapping the extent and grading the severity of pathology (Poublanc et al., 2015; Holmes et al., 2020), a conclusion also reached by others (van Niftrik et al., 2017). It is currently debated as to whether the $\tau$ slowing effect of vascular risk factors on parenchymal brain arteries can be separated from those of extra-parenchymal large vessel arterial stenoocclusive disease. 


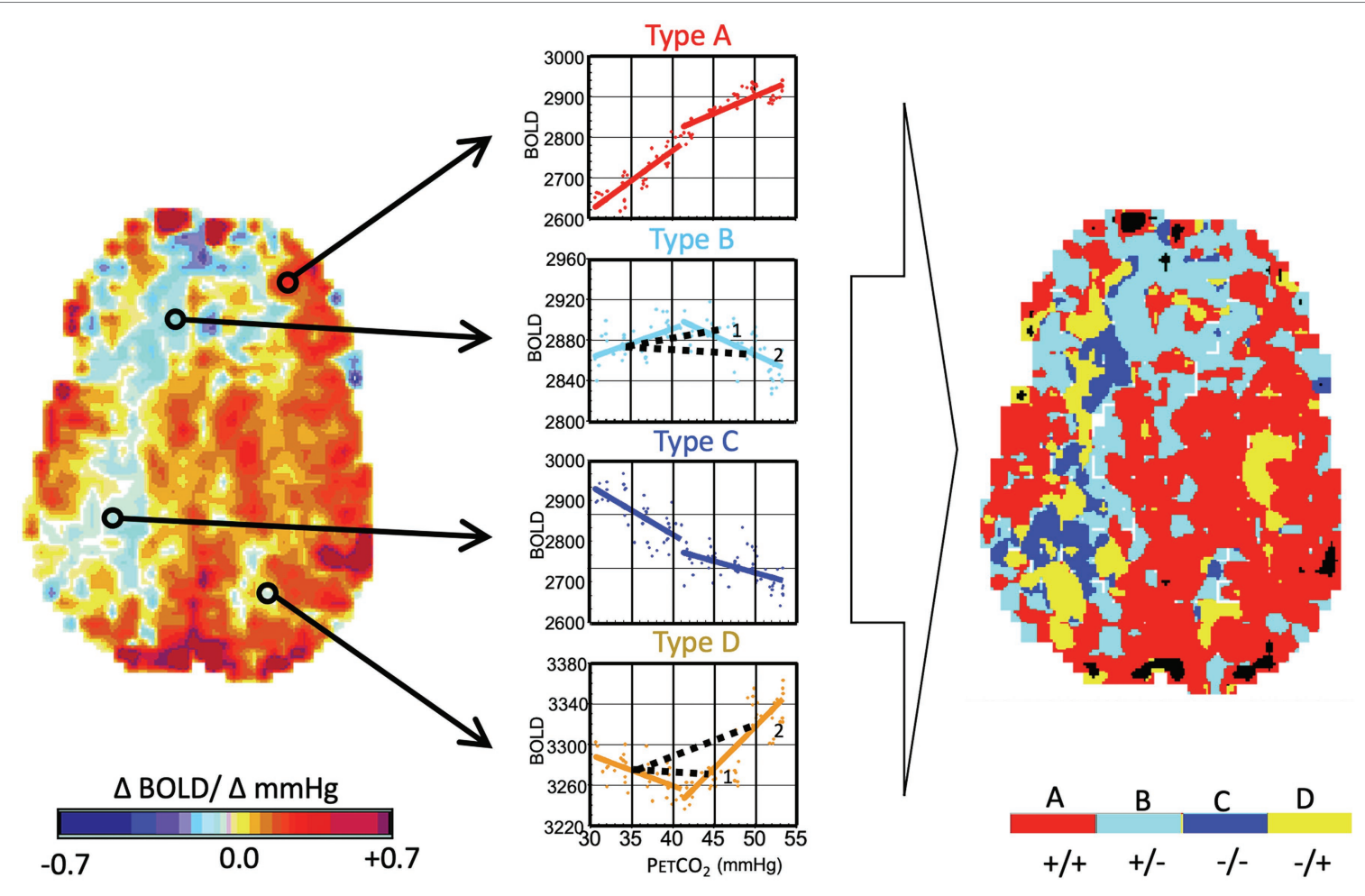

FIGURE 6 | Analysis of flow signal ( $\triangle \mathrm{BOLD})$ over a range of $\mathrm{PaCO}_{2}$ in the presence of cerebrovascular disease. Same subject as Figure 1. The PaCO ${ }_{2}$ was varied in a ramp paradigm (see Figure 3) from $10 \mathrm{mmHg}$ below baseline to $15 \mathrm{mmHg}$ above baseline. Left Map: The voxels are analyzed as CVR and color-coded as per the color scale. Right Map: This map uses the color scale to indicate the pattern of BOLD signal over the range of $\mathrm{PaCO}_{2}$. Types of response: (A) positive response with a sigmoidal shape; (B) initial positive response which then declines; (C) response which progressively declines; and (D) initial decline followed by progressive increase. In healthy people, robust response voxels overwhelmingly predominate, and the map is substantially red. Note the projection of $\mathrm{CVR}$ as calculated for a hypothetical two-point $\mathrm{PCO}_{2}$ stimulus of $45 \mathrm{mmHg}$ and $50 \mathrm{mmHg}$ for the voxels of type (B) and (D) (see 1 and 2). In the upper figure, a $\mathrm{P}_{\mathrm{ET}} \mathrm{CO}_{2}$ stimulus of $45 \mathrm{mmHg}$ results in a positive CVR but at a $\mathrm{P}_{\mathrm{ET}} \mathrm{CO}_{2}$ of $50 \mathrm{mmHg}$, CVR of the same voxel is negative, indicating "steal." In the lower figure, a $\mathrm{P}_{\mathrm{ET}} \mathrm{CO}_{2}$ of $45 \mathrm{mmHg}$ results in a negative CVR but a positive CVR at $50 \mathrm{mmHg}$. Importantly, the type map can define the regions with the greatest steal physiology, as indicated by dark blue. This can then be used as a voxel-wise ordering of severity of steal physiology. Modified from Duffin et al. (2017).

Measurement of the speed of response may be limited by the time taken for the stimulus to evolve to a steady state. Figures 7A2,B2 illustrates a range of the slowing of response to a square wave stimulus. If rather than a square wave, the $\mathrm{PaCO}_{2}$ rises to a maximum with a time constant of $\tau_{\text {stimulus, }}$ the calculated $\tau_{\text {response }}$ cannot be less. With stressors such as fixed $\mathrm{FICO}_{2}$, it is not possible to measure any $\tau$-response less than the time constant of the lung wash-in to a new $\mathrm{PCO}_{2}$. In healthy young people, this is $20-30 \mathrm{~s}$ but is longer in older people and those with expiratory flow restrictions. Consequently, measuring the intrinsic speed of the vascular response requires a stressor with a very short $\tau$-stimulus approaching a square wave, substantially changing from baseline to target $\mathrm{PaCO}_{2}$ within one breath, as is possible with SGD (Fisher et al., 2016).

From these considerations, we have drawn three further lessons:

12. CVR has two independently measurable metrics: the amplitude of response and the speed of response.

13. The measure of the speed of vascular response to a stimulus requires a stimulus shorter than the fastest vascular response time constant to be measured.
14. To measure amplitude of change, speed of change can be accounted for mathematically or physically via a slow ramp or sinusoidal stimulus paradigms.

\section{ASSESSING SINGLE SUBJECTS/ PATIENTS: WHAT IS NORMAL?}

The repeatability of a test in one person over time (Figure 9) or between two people is the key to clinical application. Assuming two subjects receive identical stimuli and are scanned with the same scanner parameters, the CVR of a ROI, or even that of a single voxel, should be comparable after accounting for day-to-day variations in subject physiology and scanner instabilities. Administering the same stimulus and using the same scan parameters over a cohort of healthy subjects enable the generation of a map of voxel-wise normative CVR values (as mean and standard deviation) controlled for anatomical location, age, sex, or any other factor. Collectively, such normative data are referred to as a "CVR atlas" (Sobczyk et al., 2015; Figure 10). 
A

\section{1}

signal voxel $\mathrm{X}$

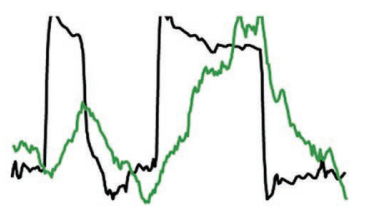

B

B signal voxel $Y$

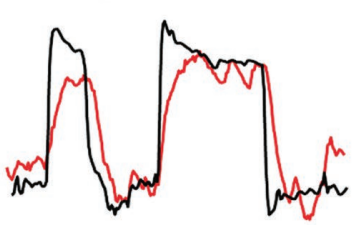

C

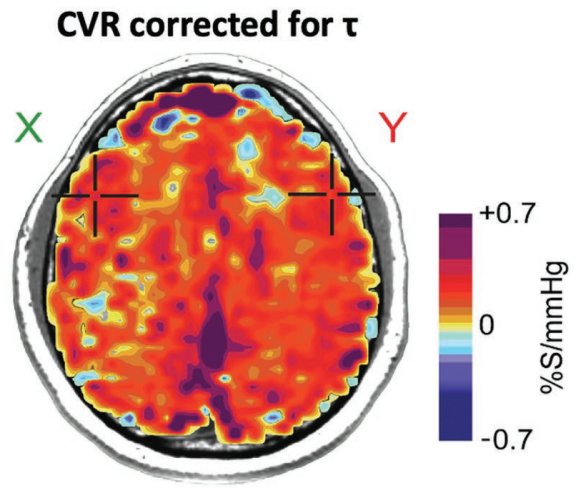

2

IF $\mathrm{x} \tau$ series
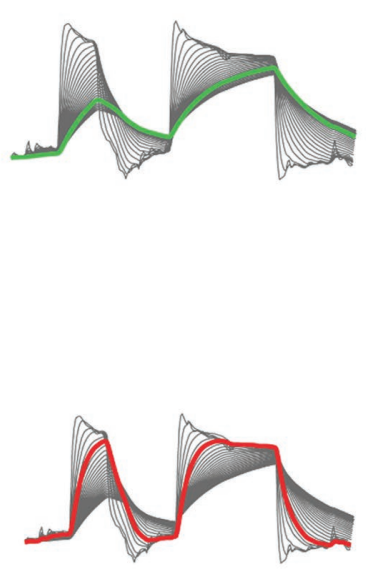

3
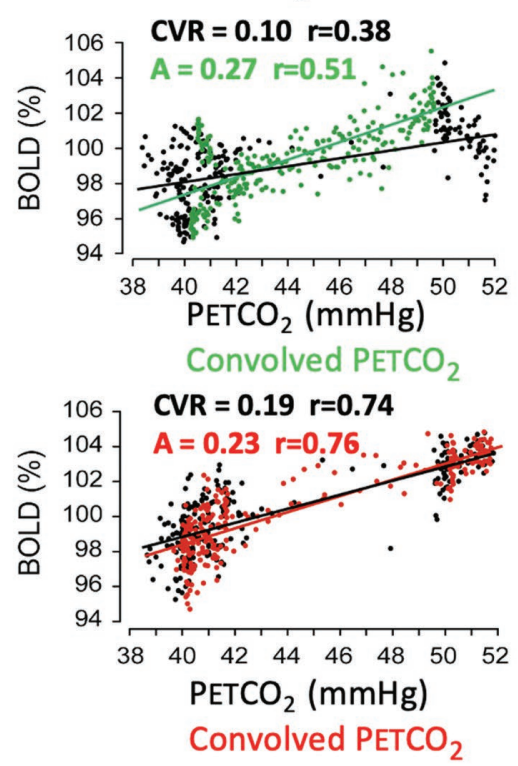

$\tau$ map

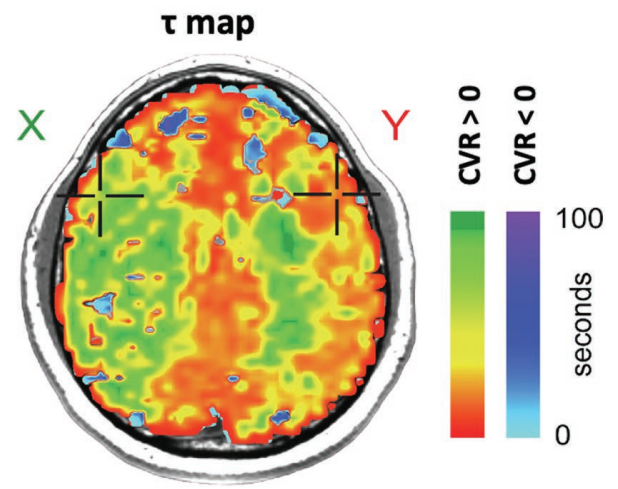

FIGURE 7 | Effect of the speed of vascular response to a stimulus on the measure of CVR. (A1, B1): $\mathrm{P}_{\mathrm{ET}} \mathrm{CO}_{2}$ and BOLD signal for voxels shown in maps in row (C) (A2, B2): multiple versions of $\mathrm{P}_{\mathrm{ET}} \mathrm{CO}_{2}$ obtained by convolving the $\mathrm{P}_{\mathrm{ET}} \mathrm{CO}_{2}$ with an exponential function of time constant $\tau$. The heavy line is the one that best fits the signal shown in $\mathbf{A} \mathbf{1}$ and $\mathbf{A} 2$, and the associated $\tau$ characterizes the speed of vascular response (see Figure $\mathbf{1}$ in Poublanc et al., 2015). (A3, B3): The black dots map the BOLD vs. $\mathrm{P}_{\mathrm{ET}} \mathrm{CO}_{2}$, and the black line indicates the associated regression line. The green and red dots are BOLD signal graphed against convolved $\mathrm{P}_{\mathrm{ET}} \mathrm{CO}_{2}$. The slopes of the green and red regression lines denote the amplitude of the signal corrected for its response time $\tau$. (C) Right figure shows the distribution of $\tau$ in an axial slice. The slowed responses (indicated by the green coloration) would tend to reduce the CVR value calculated from actual $\mathrm{P}_{\mathrm{ET}} \mathrm{CO}_{2}$ and increase the "steal" colors calculated by line of best fit alone (see images on left in Figure 4). (C): Left figure. The CVR map shows a normal CVR after mathematically correcting for the slowed $\tau$. This shows that abnormal CVR calculations without correcting for $\tau$ would be due to a slowed $\tau$.

Performing repeated CVR tests in a cohort enables the documentation of the normal range of voxel-wise test-test variability. These data can be used to assess whether repeated tests in a single subject differ over and above that due to extrinsic causes (e.g., stimulus delivery and imaging devices) of test-retest variability and therefore attributable to a disease process or surgical intervention. Such determinations are pertinent in clinical assessment and drawing conclusions from clinical data (Sobczyk et al., 2016).

From these considerations, we draw the final two lessons:

15. A standard stimulus and uniform scan parameters enable construction of an atlas of normal values and their standard deviation.
16. A merged group atlas of normative CVR metrics enables scoring a single subject/patient in terms of standard deviation differences from normal responses, thus providing clinical utility important for judging the impact of steno-occlusive disease in that individual.

\section{CONCLUSION}

Standardization and reproducibility of the $\mathrm{CO}_{2}$ stressor are fundamental to advance the use of CVR for understanding cerebral vascular physiology and pathophysiology and translating the science to the bedside. 

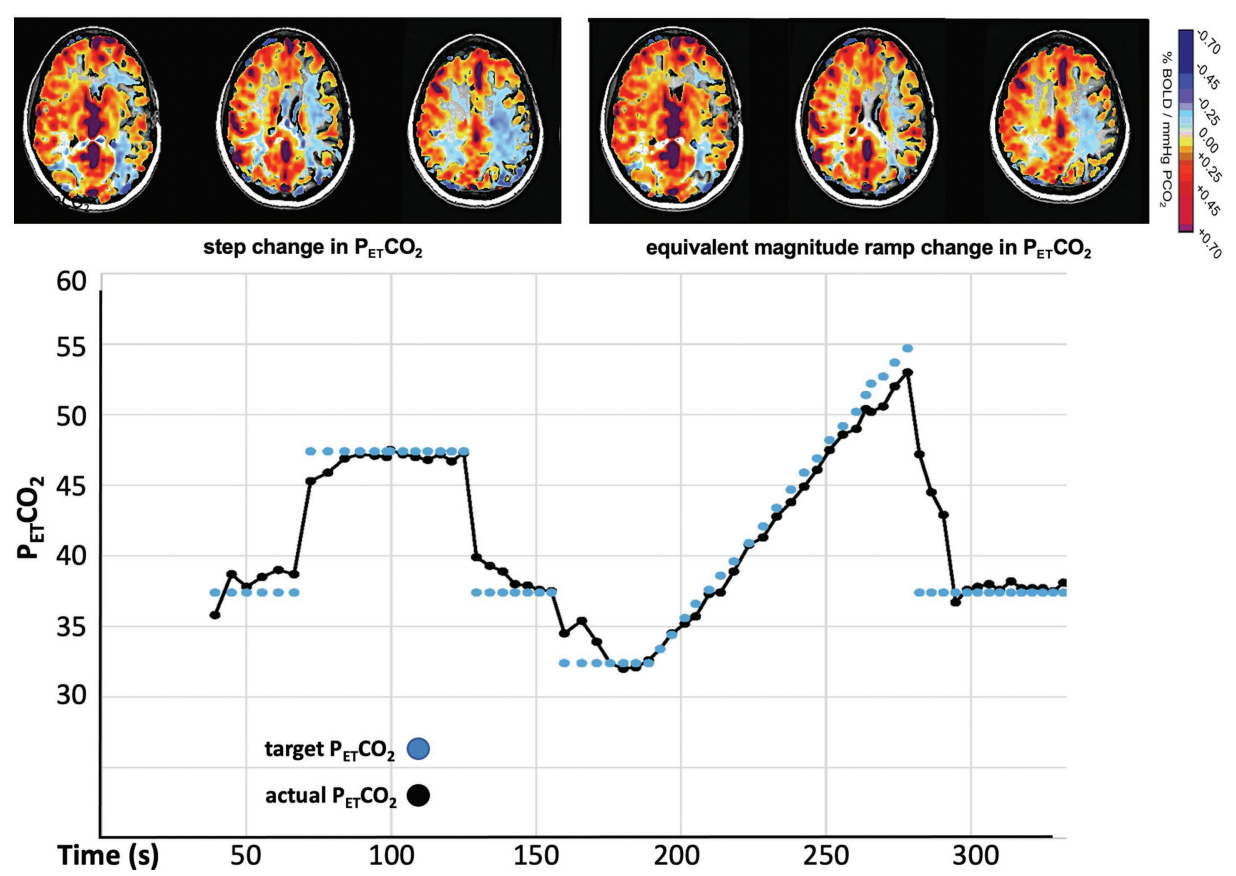

FIGURE 8 | CVR measured with a step ("box car") change and a ramp change of $\mathrm{P}_{\mathrm{ET}} \mathrm{CO}_{2}$ in a patient with moyamoya disease. The calculation of CVR after the step change indicates extensive bilateral "steal." The gradual ramp stimulus shows much reduced steal (less blue). These maps indicate that, if not accounted for, slowed response times contribute to the reduced values in the calculation of the CVR.

A

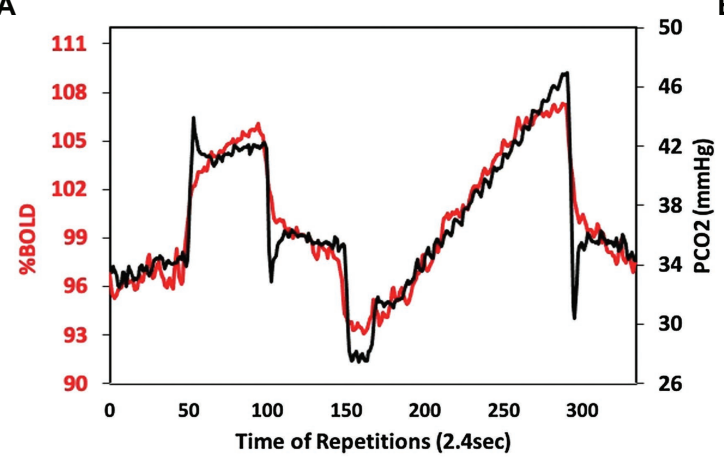

B

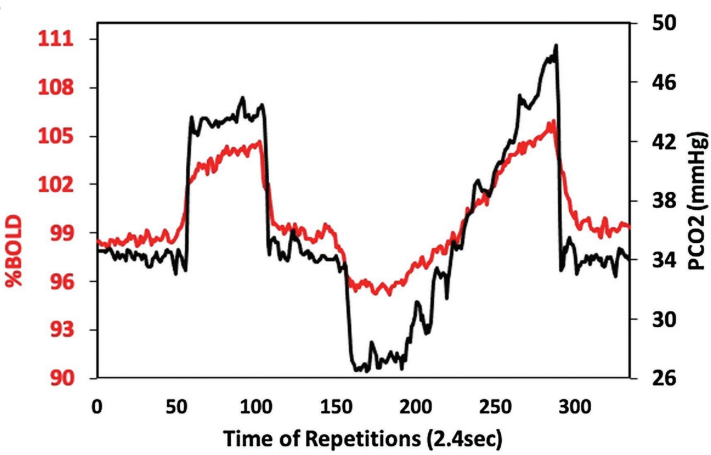

—\%BOLD Best Voxel/ROI — $\mathrm{PCO}_{2}$

FIGURE 9 | Reproducibility of the stimulus. Data from a 46-year-old female being followed for progressive narrowing of intracranial segments of both internal carotid and middle cerebral arteries. CVR scan in (A) was performed 2 years prior to CVR scan in (B) to assess the progress of hemodynamic compromise. Note the high reproducibility of the stimulus. This reproducibility enables the dampening flow response (red line) in (B) to be attributed to the vascular compromise.

We present 16 lessons (limitations, optimizations, and interpretations) acquired from two decades using CVR as a cerebrovascular stress test in about 2,000 patients with cerebrovascular disease, as well as several healthy subjects. We investigated the method of action, and thereby the optimization and limitations of the stressor, identified suitable outcome variables, and divined the sometimes very obscure physiology at which they hinted. Many, but not all, of these have been presented in one way or another in our peer-reviewed publications over the years and various journals but we believe will benefit from collation into one document. The sum of this work may lead to the development of a quantitative repeatable standardized CVR test for both clinical and research purposes. In patients, it can be used to detect and quantify hemodynamic insufficiency, follow the natural history of the disease in individual patients, and assess the response to interventions. For research, the ability to apply standardized CVR methodology for data 


\section{Z-map Construction} 1. Perform CVR tests with
standard stimulus in cohort

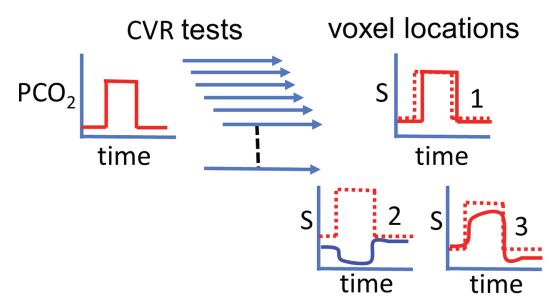

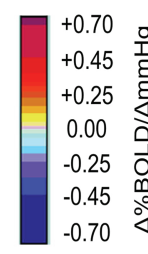

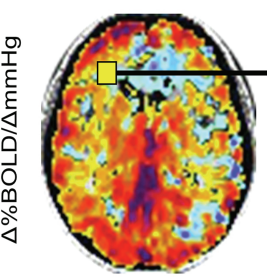

4. Patient CVR with same standard stimulus as cohort
2. Co-register all subject scans to standard space
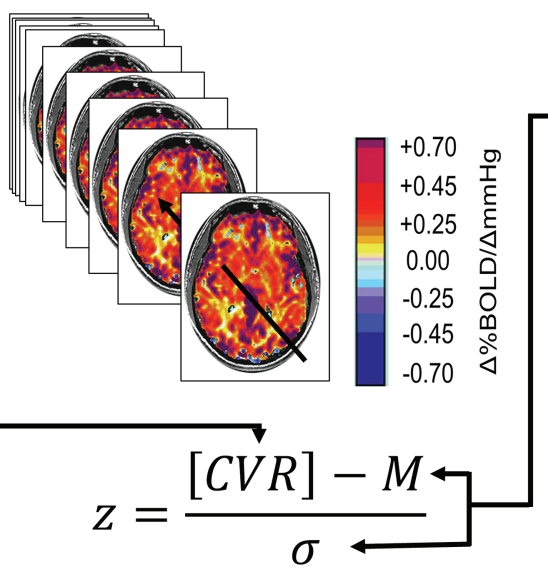

5. Calculate $z$ score for each voxel

\section{Atlas of subject mean and standard deviation for each corresponding voxel}

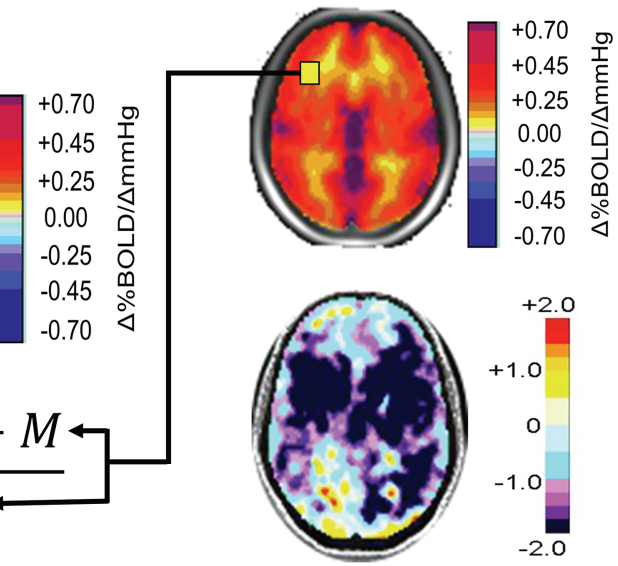

6. Map and color code $z$ scores to anatomical scans creating z-map

FIGURE 10 | Normalizing the CVR score in terms of the normal range. An identical stimulus is applied to each subject in a cohort of healthy people. CVR is calculated and mapped to standard space. Mean $(\mathrm{M})$ and standard deviation $(\sigma)$ are calculated for each voxel. A patient is administered the same test. The patient CVR is assessed as Z-scores, defined as shown in step 5. Z-scores can be color-coded and mapped over the anatomical scan to show the distribution of coherence to the mean. Figure from Fisher et al. (2018).

acquisition and quantitation is critical in any prospective clinical trial that assesses the natural history of disease and its management.

\section{DATA AVAILABILITY STATEMENT}

The data analyzed in this study is subject to the following licenses/restrictions: Anonymized data will be shared by request from any qualified investigator for purposes such as replicating procedures and results presented in the article provided that data transfer is in agreement with the University Health Network and Health Canada legislation on the general data protection regulation. Requests to access these datasets should be directed to OS, olivia.sobczyk@uhn.ca.

\section{REFERENCES}

Ainslie, P. N., and Burgess, K. R. (2008). Cardiorespiratory and cerebrovascular responses to hyperoxic and hypoxic rebreathing: effects of acclimatization to high altitude. Respir. Physiol. Neurobiol. 161, 201-209. doi: 10.1016/j. resp.2008.02.003

Al-Khazraji, B. K., Shoemaker, L. N., Gati, J. S., Szekeres, T., and Shoemaker, J. K. (2019). Reactivity of larger intracranial arteries using 7 T MRI in young adults. J. Cereb. Blood Flow Metab. 39, 1204-1214. doi: 10.1177/0271678X187 62880

Bang, O. Y., Saver, J. L., Buck, B. H., Alger, J. R., Starkman, S., Ovbiagele, B., et al. (2008). Impact of collateral flow on tissue fate in acute ischaemic stroke. J. Neurol. Neurosurg. Psychiatry 79, 625-629. doi: 10.1136/ jnnp.2007.132100

\section{ETHICS STATEMENT}

The studies involving human participants were reviewed and approved by University Health Network, Toronto, Canada. The patients/participants provided their written informed consent to participate in the studies. Written informed consent was obtained from the individual(s) for the publication of any potentially identifiable images or data included in this article.

\section{AUTHOR CONTRIBUTIONS}

OS, JF, LV, JD, JAF and DJM drafted the manuscript. All authors participated in the feedback and writing process following the initial drafting of the manuscript.

Battisti-Charbonney, A., Fisher, J., and Duffin, J. (2011). The cerebrovascular response to carbon dioxide in humans. J. Physiol. 589, 3039-3048. doi: 10.1113/jphysiol.2011.206052

Bhogal, A. A., Philippens, M. E., Siero, J. C., Fisher, J. A., Petersen, E. T., Luijten, P. R., et al. (2015). Examining the regional and cerebral depthdependent BOLD cerebrovascular reactivity response at 7T. NeuroImage 114, 239-248. doi: 10.1016/j.neuroimage.2015.04.014

Bhogal, A., Siero, J. C., Fisher, J. A., Froeling, M., Luijten, P., Philippens, M., et al. (2014). Investigating the non-linearity of the BOLD cerebrovascular reactivity response to targeted hypo/hypercapnia at 7T. NeuroImage 98, 296-305. doi: 10.1016/j.neuroimage.2014.05.006

Blockley, N. P., Driver, I. D., Francis, S. T., Fisher, J. A., and Gowland, P. A. (2011). An improved method for acquiring cerebrovascular reactivity maps. Magn. Reson. Med. 65, 1278-1286. doi: 10.1002/mrm.22719 
Brawley, B. W. (1968). The pathophysiology of intracerebral steal following carbon dioxide inhalation, an experimental study. Scand. J. Clin. Lab. Invest. Suppl. 102:XIII:B. doi: 10.3109/00365516809169045

Burley, C. V., Lucas, R. A. I., Whittaker, A. C., Mullinger, K., and Lucas, S. J. E. (2020). The $\mathrm{CO}_{2}$ stimulus duration and steady-state time-point used for data extraction alters the cerebrovascular reactivity outcome measure. Exp. Physiol. 105, 893-903. doi: 10.1113/EP087883

Coverdale, N. S., Gati, J. S., Opalevych, O., Perrotta, A., and Shoemaker, J. K. (2014). Cerebral blood flow velocity underestimates cerebral blood flow during modest hypercapnia and hypocapnia. J. Appl. Physiol. 117, 1090-1096. doi: 10.1152/japplphysiol.00285.2014

Dahl, A., Russell, D., Rootwelt, K., Nyberg-Hansen, R., and Kerty, E. (1995). Cerebral vasoreactivity assessed with transcranial Doppler and regional cerebral blood flow measurements. Dose, serum concentration, and time course of the response to acetazolamide. Stroke 26, 2302-2306. doi: 10.1161/01. STR.26.12.2302

Duffin, J., and Mcavoy, G. V. (1988). The peripheral-chemoreceptor threshold to carbon dioxide in man. J. Physiol. 406, 15-26. doi: 10.1113/jphysiol.1988. sp017365

Duffin, J., Sobczyk, O., Crawley, A. P., Poublanc, J., Mikulis, D. J., and Fisher, J. A. (2015). The dynamics of cerebrovascular reactivity shown with transfer function analysis. NeuroImage 114, 207-216. doi: 10.1016/ j.neuroimage.2015.04.029

Duffin, J., Sobczyk, O., Crawley, A., Poublanc, J., Venkatraghavan, L., Sam, K., et al. (2017). The role of vascular resistance in BOLD responses to progressive hypercapnia. Hum. Brain Mapp. 38, 5590-5602. doi: 10.1002/hbm.23751

Duffin, J., Sobczyk, O., Mcketton, L., Crawley, A., Poublanc, J., Venkatraghavan, L., et al. (2018). Cerebrovascular resistance: the basis of cerebrovascular reactivity. Front. Neurosci. 12:409. doi: 10.3389/fnins.2018.00409

Fierstra, J., Machina, M., Battisti-Charbonney, A., Duffin, J., Fisher, J. A., and Minkovich, L. (2011). End-inspiratory rebreathing reduces the end-tidal to arterial $\mathrm{PCO}_{2}$ gradient in mechanically ventilated pigs. Intensive Care Med. 37, 1543-1550. doi: 10.1007/s00134-011-2260-y

Fierstra, J., Sobczyk, O., Battisti-Charbonney, A., Mandell, D. M., Poublanc, J., Crawley, A. P., et al. (2013). Measuring cerebrovascular reactivity: what stimulus to use? J. Physiol. 591, 5809-5821. doi: 10.1113/jphysiol. 2013.259150

Fisher, J. A. (2016). The $\mathrm{CO}_{2}$ stimulus for cerebrovascular reactivity: fixing inspired concentrations vs. targeting end-tidal partial pressures. J. Cereb. Blood Flow Metab. 36, 1004-1011. doi: 10.1177/0271678X16639326

Fisher, J. A., Iscoe, S., and Duffin, J. (2016). Sequential gas delivery provides precise control of alveolar gas exchange. Respir. Physiol. Neurobiol. 225, 60-69. doi: 10.1016/j.resp.2016.01.004

Fisher, J. A., Sobczyk, O., Crawley, A., Poublanc, J., Dufort, P., Venkatraghavan, L., et al. (2017). Assessing cerebrovascular reactivity by the pattern of response to progressive hypercapnia. Hum. Brain Mapp. 38, 3415-3427. doi: 10.1002/ hbm. 23598

Fisher, J. A., Venkatraghavan, L., and Mikulis, D. J. (2018). Magnetic resonance imaging-based cerebrovascular reactivity and hemodynamic reserve. Stroke 49, 2011-2018. doi: 10.1161/STROKEAHA.118.021012

Grossmann, W. M., and Koeberle, B. (2000). The dose-response relationship of acetazolamide on the cerebral blood flow in normal subjects. Cerebrovasc. Dis. 10, 65-69. doi: 10.1159/000016027

Harper, A. M., and Glass, H. I. (1965). Effect of alterations in the arterial carbon dioxide tension on the blood flow through the cerebral cortex at normal and low arterial blood pressures. J. Neurol. Neurosurg. Psychiatry 28, 449-452. doi: 10.1136/jnnp.28.5.449

Hoge, R. D., Atkinson, J., Gill, B., Crelier, G. R., Marrett, S., and Pike, G. B. (1999). Investigation of BOLD signal dependence on cerebral blood flow and oxygen consumption: the deoxyhemoglobin dilution model. Magn. Reson. Med. 42, 849-863.

Holmes, K. R., Tang-Wai, D., Sam, K., Mcketton, L., Poublanc, J., Crawley, A. P., et al. (2020). Slowed temporal and parietal cerebrovascular response in patients with Alzheimer's disease. Can. J. Neurol. Sci. 47, 366-373. doi: $10.1017 /$ cjn. 2020.30

Ide, K., Eliasziw, M., and Poulin, M. J. (2003). Relationship between middle cerebral artery blood velocity and end-tidal $\mathrm{PCO}_{2}$ in the hypocapnichypercapnic range in humans. J. Appl. Physiol. 95, 129-137. doi: 10.1152/ japplphysiol.01186.2002
Ito, S., Mardimae, A., Han, J., Duffin, J., Wells, G., Fedorko, L., et al. (2008). Non-invasive prospective targeting of arterial $\mathrm{PCO}_{2}$ in subjects at rest. $J$. Physiol. 586, 3675-3682. doi: 10.1113/jphysiol.2008.154716

Jones, N. L., Robertson, D. G., Kane, J. W., and Moran Campbell, E. J. (1972). Effect of $\mathrm{PCO}_{2}$ level on alveolar-arterial $\mathrm{PCO}_{2}$ difference during rebreathing. J. Appl. Physiol. 32, 782-787. doi: 10.1152/jappl.1972.32.6.782

Kety, S. S., and Schmidt, C. F. (1948). The effects of altered arterial tension of carbon dioxide and oxygen on cerebral blood flow and cerebral oxygen consumption of normal men. J. Clin. Investig. 27, 484-492. doi: 10.1172/ JCI101995

Kontos, H. A. (1989). Validity of cerebral arterial blood flow calculations from velocity measurements. Stroke 20, 1-3. doi: 10.1161/01.STR.20.1.1

Kulik, T., Kusano, Y., Aronhime, S., Sandler, A. L., and Winn, H. R. (2008). Regulation of cerebral vasculature in normal and ischemic brain. Neuropharmacology 55, 281-288. doi: 10.1016/j.neuropharm.2008.04.017

Mardimae, A., Balaban, D. Y., Machina, M. A., Han, J. S., Katznelson, R., Minkovich, L. L., et al. (2012). The interaction of carbon dioxide and hypoxia in the control of cerebral blood flow. Pflugers Arch. 464, 345-351. doi: 10.1007/s00424-012-1148-1

McDonald, M. J., Montgomery, V. L., Cerrito, P. B., Parrish, C. J., Boland, K. A., and Sullivan, J. E. (2002). Comparison of end-tidal $\mathrm{CO}_{2}$ and $\mathrm{PaCO}_{2}$ in children receiving mechanical ventilation. Pediatr. Crit. Care Med. 3, 244-249. doi: 10.1097/00130478-200207000-00008

McKetton, L., Cohn, M., Tang-Wai, D. F., Sobczyk, O., Duffin, J., Holmes, K. R., et al. (2019). Cerebrovascular resistance in healthy aging and mild cognitive impairment. Front. Aging Neurosci. 11:79. doi: 10.3389/fnagi.2019.00079

McKetton, L., Sobczyk, O., Duffin, J., Poublanc, J., Sam, K., Crawley, A. P., et al. (2018). The aging brain and cerebrovascular reactivity. NeuroImage 181, 132-141. doi: 10.1016/j.neuroimage.2018.07.007

Peebles, K., Celi, L., Mcgrattan, K., Murrell, C., Thomas, K., and Ainslie, P. N. (2007). Human cerebrovascular and ventilatory $\mathrm{CO}_{2}$ reactivity to end-tidal, arterial and internal jugular vein $\mathrm{PCO}_{2}$. J. Physiol. 584, 347-357. doi: 10.1113/ jphysiol.2007.137075

Poublanc, J., Crawley, A. P., Sobczyk, O., Montandon, G., Sam, K., Mandell, D. M., et al. (2015). Measuring cerebrovascular reactivity: the dynamic response to a step hypercapnic stimulus. J. Cereb. Blood Flow Metab. 35, 1746-1756. doi: $10.1038 / \mathrm{jcbfm} .2015 .114$

Poulin, M. J., Liang, P. J., and Robbins, P. A. (1996). Dynamics of the cerebral blood flow response to step changes in end- tidal $\mathrm{PCO}_{2}$ and $\mathrm{PO}_{2}$ in humans. J. Appl. Physiol. 81, 1084-1095. doi: 10.1152/jappl.1996.81.3.1084

Prisman, E., Slessarev, M., Azami, T., Nayot, D., Milosevic, M., and Fisher, J. (2007). Modified oxygen mask to induce target levels of hyperoxia and hypercarbia during radiotherapy: a more effective alternative to carbogen. Int. J. Radiat. Biol. 83, 457-462. doi: 10.1080/09553000701370894

Reinhard, M., Schwarzer, G., Briel, M., Altamura, C., Palazzo, P., King, A., et al. (2014). Cerebrovascular reactivity predicts stroke in high-grade carotid artery disease. Neurology 83, 1424-1431. doi: 10.1212/WNL.0000000000000888

Reivich, M. (1964). Arterial $\mathrm{PCO}_{2}$ and cerebral hemodynamics. Am. J. Phys. 206, 25-35. doi: 10.1152/ajplegacy.1964.206.1.25

Ringelstein, E. B., Sievers, C., Ecker, S., Schneider, P. A., and Otis, S. M. (1988). Noninvasive assessment of $\mathrm{CO}_{2}$-induced cerebral vasomotor response in normal individuals and patients with internal carotid artery occlusions. Stroke 19, 963-969. doi: 10.1161/01.STR.19.8.963

Ringelstein, E. B., Van Eyck, S., and Mertens, I. (1992). Evaluation of cerebral vasomotor reactivity by various vasodilating stimuli: comparison of $\mathrm{CO}_{2}$ to acetazolamide. J. Cereb. Blood Flow Metab. 12, 162-168. doi: 10.1038/ jcbfm. 1992.20

Robbins, P. A., Swanson, G. D., Micco, A. J., and Schubert, W. P. (1982). A fast gas-mixing system for breath-to-breath respiratory control studies. J. Appl. Physiol. 52, 1358-1362. doi: 10.1152/jappl.1982.52.5.1358

Saito, H., Ogasawara, K., Suzuki, T., Kuroda, H., Kobayashi, M., Yoshida, K., et al. (2011). Adverse effects of intravenous acetazolamide administration for evaluation of cerebrovascular reactivity using brain perfusion singlephoton emission computed tomography in patients with major cerebral artery steno-occlusive diseases. Neurol. Med. Chir. 51, 479-483. doi: 10.2176/ nmc.51.479

Sheth, S. A., Sanossian, N., Hao, Q., Starkman, S., Ali, L. K., Kim, D., et al. (2016). Collateral flow as causative of good outcomes in endovascular stroke therapy. J. Neurointerv. Surg. 8, 2-7. doi: 10.1136/neurintsurg-2014-011438 
Slessarev, M., Han, J., Mardimae, A., Prisman, E., Preiss, D., Volgyesi, G., et al. (2007). Prospective targeting and control of end-tidal $\mathrm{CO}_{2}$ and $\mathrm{O}_{2}$ concentrations. J. Physiol. 581, 1207-1219. doi: 10.1113/jphysiol.2007.129395

Sobczyk, O., Battisti-Charbonney, A., Fierstra, J., Mandell, D. M., Poublanc, J., and Crawley, A. P. (2014). A conceptual model for $\mathrm{CO}_{2}$-induced redistribution of cerebral blood flow with experimental confirmation using BOLD MRI. NeuroImage 92, 56-68. doi: 10.1016/j.neuroimage.2014.01.051

Sobczyk, O., Battisti-Charbonney, A., Poublanc, J., Crawley, A. P., Sam, K., Fierstra, J., et al. (2015). Assessing cerebrovascular reactivity abnormality by comparison to a reference atlas. J. Cereb. Blood Flow Metab. 35, 213-220. doi: $10.1038 /$ jcbfm.2014.184

Sobczyk, O., Crawley, A. P., Poublanc, J., Sam, K., Mandell, D. M., Mikulis, D. J., et al. (2016). Identifying significant changes in cerebrovascular reactivity to carbon dioxide. AJNR Am. J. Neuroradiol. 37, 818-824. doi: 10.3174/ajnr.A4679

Spano, V. R., Mandell, D. M., Poublanc, J., Sam, K., Battisti-Charbonney, A., Pucci, O., et al. (2013). $\mathrm{CO}_{2}$ blood oxygen level-dependent MR mapping of cerebrovascular reserve in a clinical population: safety, tolerability, and technical feasibility. Radiology 266, 592-598. doi: 10.1148/radiol.12112795

Symon, L. (1969). The concept of intracerebral steal. Int. Anesthesiol. Clin. 7, 597-615. doi: 10.1097/00004311-196907030-00009

Tan, B. Y., Wan-Yee, K., Paliwal, P., Gopinathan, A., Nadarajah, M., Ting, E., et al. (2016). Good intracranial collaterals trump poor ASPECTS (Alberta Stroke Program Early CT Score) for intravenous thrombolysis in anterior circulation acute ischemic stroke. Stroke 47, 2292-2298. doi: 10.1161/ STROKEAHA.116.013879

Totaro, R., Marini, C., Baldassarre, M., and Carolei, A. (1999). Cerebrovascular reactivity evaluated by transcranial Doppler: reproducibility of different methods. Cerebrovasc. Dis. 9, 142-145. doi: 10.1159/000015943

Tymko, M. M., Hoiland, R. L., Kuca, T., Boulet, L. M., Tremblay, J. C., Pinske, B. K., et al. (2016). Measuring the human ventilatory and cerebral blood flow response to $\mathrm{CO}_{2}$ : a technical consideration for the end-tidalto-arterial gas gradient. J. Appl. Physiol. 120, 282-296. doi: 10.1152/ japplphysiol.00787.2015

van Niftrik, C. H. B., Piccirelli, M., Bozinov, O., Pangalu, A., Fisher, J. A., Valavanis, A., et al. (2017). Iterative analysis of cerebrovascular reactivity dynamic response by temporal decomposition. Brain Behav. 7:e00705. doi: 10.1002/brb3.705
Verbree, J., Bronzwaer, A.-S. G. T., Ghariq, E., Versluis, M. J., Daemen, M. J. A. P., Van Buchem, M. A., et al. (2014). Assessment of middle cerebral artery diameter during hypocapnia and hypercapnia in humans using ultra-high-field MRI. Appl. Physiol. 117, 1084-1089. doi: 10.1152/japplphysiol.00651.2014

Vesely, A., Sasano, H., Volgyesi, G., Somogyi, R., Tesler, J., Fedorko, L., et al. (2001). MRI mapping of cerebrovascular reactivity using square wave changes in end-tidal $\mathrm{PCO}_{2}$. Magn. Reson. Med. 45, 1011-1013. doi: 10.1002/mrm.1134

Willie, C. K., Macleod, D. B., Shaw, A. D., Smith, K. J., Tzeng, Y. C., Eves, N. D., et al. (2012). Regional brain blood flow in man during acute changes in arterial blood gases. J. Physiol. 590, 3261-3275. doi: 10.1113/jphysiol.2012.228551

Yao, J. F., Yang, H. S., Wang, J. H., Liang, Z., Talavage, T. M., Tamer, G. G. Jr., et al. (2021). A novel method of quantifying hemodynamic delays to improve hemodynamic response, and CVR estimates in CO2 challenge fMRI. J. Cereb. Blood Flow Metab. doi: 10.1177/0271678X20978582 [Epub ahead of print].

Conflict of Interest: JAF and DJM contributed to the development of the automated end-tidal targeting device, RespirAct ${ }^{\mathrm{TM}}$ (Thornhill Research Inc., (TRI)) used in the figure studies mentioned and have equity in the company. RespirAct ${ }^{\mathrm{TM}}$ is not currently a commercial product but is made available for REB-approved research. OS and JD received salary support from TRI. TRI provided no other support for the study.

The remaining authors declare that the research was conducted in the absence of any commercial or financial relationships that could be construed as a potential conflict of interest.

The reviewer $\mathrm{RH}$ declared a past collaboration with one of the authors JAF to the handling editor.

Copyright (C) 2021 Sobczyk, Fierstra, Venkatraghavan, Poublanc, Duffin, Fisher and Mikulis. This is an open-access article distributed under the terms of the Creative Commons Attribution License (CC BY). The use, distribution or reproduction in other forums is permitted, provided the original author(s) and the copyright owner(s) are credited and that the original publication in this journal is cited, in accordance with accepted academic practice. No use, distribution or reproduction is permitted which does not comply with these terms. 